\title{
LA ENSEÑNANA DE LA ÉTICA EN TIEMPOS DE RELATIVISMO
}

\section{Alberto M. Sánchez}

Universidad Austral

estudioamsanchez@gmail.com

\section{Introducción}

Hablar de ética en un mundo dominado por el relativismo ${ }^{1}$ es una tarea sumamente compleja. ${ }^{2}$ No porque se niegue que el ser humano debe obrar éticamente, sino por la dificultad casi insalvable de acordar qué es "lo ético". Por otra parte, existe una tendencia a pensar que lo ético y lo $\mathrm{moral}^{3}$ son cuestiones "religiosas", lo que produce en no pocas personas un rechazo instantáneo. Finalmente, una posición egocéntrica, sobre la que volveré más adelante, lleva a muchos a erigirse en el punto de referencia de lo moral.

Estas líneas en modo alguno pretenden pasar revista por las corrientes filosóficas que se ocupan del tema, más allá de algunas referencias puntuales. El objetivo es, simplemente, brindar algunas pautas de reflexión para la enseñanza de la Ética, en particular en el mundo universitario. Sin perjuicio de la enorme riqueza que implica la lectura, estudio y análisis de los autores que se ocupan del tema, ${ }^{4}$ mi propuesta es sugerir elementos que permitan a cada uno, en un proceso de introspección y en el marco del aprendizaje áulico, descubrir en su propio interior las respuestas a las preguntas fundamentales de la existencia: ¿quién soy?, ¿por qué soy?, ¿para qué soy?

1 "El relativismo representa la eterna objeción a la pretensión de buscar racionalmente el contenido objetivo, no subjetivo, de la palabra 'bueno”. (Ayllón, 2008, p. 15)

2 Escribe Sotelo de Andreau (2007): "Poco a poco la ética se convirtió en un tema exótico de investigación, no por la caracterización de los estudiosos, sino por el interés que por ella se muestra. En el proceso de difusión aparecen obstáculos puestos en juego tanto el emisor como el receptor, pareciera como que no se desea internalizarla. La ética se ha convertido en una imagen virtual" (p. 53).

3 En este trabajo se utilizarán las expresiones "ética" y "moral" como sinónimos.

4 Recomiendo acudir, entre otros, a Cassagne (2015), Hervada (2000), Massini Correas (2005), Rodríguez-Arana Muñoz (2004), Santiago (2002), Sarmiento García (2003) Soto Kloss (2002) y Vigo (2000). 
A fin de no abusar de la diagnosis, diré brevemente que advierto, entre otras, las siguientes características en nuestra cultura globalizada:

1. La relativización del concepto "verdad", manifestada cotidianamente en frases tales como: "esa es tu verdad y yo tengo mi verdad", "nadie es dueño de la verdad", "no hay verdades absolutas", "todo depende del cristal con el que se lo mire", etcétera.

2. La confusión entre "verdad" y "opinión".

3. La superficialidad en los análisis y la banalización en las comunicaciones.

4. La primacía del "tener razón" por sobre el esfuerzo por encontrar la verdad.

En todos los casos, lo que subyace es una renuncia al esfuerzo por pensar en profundidad, por llegar hasta las últimas consecuencias en el desarrollo de un argumento, por someter cada una de las afirmaciones a mínimos testeos de coherencia. Muchas veces, la primera idea que viene a la cabeza se convierte en sentencia y adquiere validez universal y definitiva simplemente porque se instaló en la cabeza del pensante, quien, cuando se vea acorralado en un debate ante la inconsistencia e incongruencia de su idea, lejos de reconocer que es errónea, apelará rápidamente al ya mencionado latiguillo "es mi verdad". Con ello se finiquita toda discusión y queda "a salvo" de la verdad su opinión equivocada.

Creo que todos hemos tenido la experiencia de que algún interlocutor, aun advirtiendo con claridad que su parecer sobre algún tema determinado no es coherente, no está dispuesto a modificar su esquema de valorización por cuanto ello le llevaría a tener que cuestionarse a sí mismo. Poner en juego todo el propio sistema de valoraciones no es algo que muchos estén dispuestos a aceptar. En cierta forma, es como empezar de nuevo.

Por último, mencionaré un hecho bien conocido por algunos e intuido por el resto: buscar la verdad, hallarla y servirla con la propia vida es un proceso difícil y arduo que nos pone a contramano de la cultura imperante y que en no pocos casos exige un auténtico heroísmo. La palabra clave, cuando hablamos de ética, es "coherencia", y no es fácil ser coherente en un mundo que invita a acomodarse, a adaptarse, a abandonar las posiciones "extremas", "cerradas" y "rígidas" para licuar la vida en un mar de permisivismo acomodaticio.

El "problema" de la verdad no es su contenido, sino que nos exige entregarle la vida. No la entrega existencial del romanticismo, sino la de cada acto. "Nunca es triste la verdad, lo que no tiene es remedio", dice Serrat en la canción Sinceramente tuyo. El relativismo invita a recorrer el camino inverso, a construir para mi vida una "verdad" que no sea un problema, que no me comprometa, 
que no me exija, que sea tan maleable como para ajustarse a mis deseos, que abarque todo lo que yo quiera introducir en mi cotidianeidad y, sobre todo, que renuncie a su pretensión de definitividad porque quién sabe si lo que hoy me agrada y me conviene me agradará o convendrá mañana.

Así, la relación de esencial intricación entre verdad y ética se desdibuja por completo y desaparece toda referencia que permita juzgar los propios actos.

\section{Vinculación de la ética con la cosmovisión del hombre}

Existe una indudable relación entre la valoración de los comportamientos y la cosmovisión que el hombre posee en cada etapa de la historia. No he de referirme, por razones de espacio, a las distintas cosmovisiones que pueden verificarse a lo largo de la historia de la humanidad. Solamente he de indicar acá que los últimos siglos han sido testigos del paso del teocentrismo (Edad Media) al antropocentrismo (Renacimiento, Edad Moderna) y de este al actual egocentrismo.

Primero, fue el desplazamiento de Dios, considerado centro del universo y autor de lo creado, para entronizar al hombre como centro y medida de todo. Hoy, ya no es "el hombre" el centro, sino el "yo". Esto, que dicho así parece una exageración, encuentra a poco andar un correlato indiscutible en la cotidianeidad. Así, nos descubrimos pensando -o afirmando- que tal persona es buena o mala porque ha sido buena o mala conmigo, que tal otra es muy inteligente porque coincide con mi forma de pensar, o que aquella es valiosa porque persigue y defiende los mismos intereses que persigo y defiendo yo. Los ejemplos podrían multiplicarse, pero para terminar enfatizando siempre la misma conclusión: la referencia de lo bueno, lo sabio, lo valioso y lo valiente soy yo.

Es la "ética del egocentrismo", que pretende convencernos de que son nuestros pasos los que indican el camino correcto sin importar en qué dirección van. No existe una adecuación del pensamiento y de la conducta a unos valores determinados a priori como tales, sino al revés: mi pensamiento actual y mis actos son los valores a seguir hoy.

Para la ética del egocentrismo es bueno lo que me conviene a mí, lo que me da placer, lo que me otorga poder, lo que me produce rédito económico, social o profesional, lo que está en sintonía con mi modo de actuar, lo que coincide con mi forma de pensar. El egocéntrico, aunque no se dé cuenta, piensa: "yo tengo mi ética". O, lo que es lo mismo, "yo soy la ética".

Por todo esto es que suelo proponerles a mis alumnos que respondan a dos 
preguntas esenciales, en cuyas respuestas está la definición del contenido íntegro de la cuestión ética. La primera de esas preguntas es: ¿hay una ética o muchas éticas? Para responder a esta pregunta, es imprescindible indagar primero sobre la relación de la ética con otras realidades.

\section{Relaciones de la Ética}

\subsection{Relaciones entre ética, fe y razón}

Enseñó Juan Pablo II (1998): "La fe y la razón son como las dos alas con las cuales el espíritu humano se eleva hacia la contemplación de la verdad”. Jamás la fe y la razón son incompatibles entre sí y a las más preclaras mentes de todos los tiempos les ha sido evidente que las verdades de la fe no repugnan ni obstaculizan la inteligencia humana. La mentalidad cientista, que "solo reconoce como verdad lo que la ciencia puede demostrar ${ }^{6}$ configura un peligroso reduccionismo, ya que el mismo hombre es mucho más que lo que la ciencia puede probar.

Es necesario, por otra parte, decir que la fe es un don y que la razón solo puede dejarnos en el umbral de la fe. No se trata, en este punto, de la certeza de unas ideas, sino de la experiencia vital de una comunicación personal con el Creador. Por eso, un literato ganador del Premio Nobel, André Gide, pudo decir: "En las palabras de Cristo hay más luz que en cualquiera otra palabra humana. Esto [...] no parece ser suficiente para que uno sea cristiano. Además de ello hay que creer. Ahora bien, yo no creo" (Pieper, 1993, p. 8).

Sin embargo, algunos llevan su ausencia de fe un paso más allá: se escandalizan por lo que las religiones llaman "misterios", es decir, verdades que la inteligencia no puede alcanzar acabadamente por sí misma, pero que igualmente se tienen como tales. Esgrimen que en el actual nivel de evolución de la inteligencia humana creer en "misterios" es algo insultante a esta. No obstante, lo que puede constatarse con claridad es que los únicos "misterios" que a tales personas molestan son los misterios de la fe. Conviven sin problema alguno todos los días de su vida con cientos de "misterios" que no pueden, subjetivamente, explicar, como por ejemplo: porqué se prende una luz cuando acciono una perilla, o porqué vuela un avión sin que nadie lo empuje por detrás, o porqué cuando hablo por celular escucho una voz en ausencia del hablante. De hecho,

5 Cfr. Sánchez (2017).

6 CELAM, Documento de Puebla No 315: "En esta visión, sólo se reconoce como verdad lo que la ciencia puede demostrar; el mismo hombre se reduce a su definición científica. En nombre de la ciencia todo se justifica, incluso lo que constituye una afrenta a la dignidad humana”. 
somos subjetivamente incapaces de explicar casi nada de la fenomenología que nos rodea. Se dirá, con razón, que hay quien sí lo puede explicar, lo cual es cierto, pero eso no quita que quienes se sienten incómodos con los misterios de la fe no tengan problema alguno en vivir rodeados de misterios, es decir, de infinidad de aconteceres que no pueden explicar por sí mismos. Con toda razón ha escrito García (2006) que "[...] una clara expresión del actual secularismo es ese afán de autonomía plena, porque cree que es verdad sólo aquello que él mismo puede verificar y controlar" (p. 27).

Por otra parte, en cada época de la historia se descubre que infinidad de "verdades" científicas eran groseros errores que quedaron luego en evidencia ante la evolución de la tecnología, lo que a cualquier persona con un simple dejo de humildad le lleva a pensar que lo que hoy la ciencia considera incuestionable puede ser revisado mañana ante nuevas evidencias. Solo la soberbia egocéntrica es capaz de sostener que las "verdades científicas" de hoy son infalibles e inmutables.

Finalmente, es esencial entender que todos, sin excepción, somos creyentes, y lo somos por la misma razón. Pieper (1993) explica con sabiduría que "creer significa: creer algo a alguien" (p. 6). Suelo preguntar a mis alumnos si "saben" o "creen" que son hijos de sus padres, y después de algunos instantes de perplejidad la conclusión es clara: ninguno de ellos se ha hecho una prueba de ADN para "saber" que es hijo de sus padres. Lo "creen" porque sus padres siempre se los dijeron. Creen esto porque les creen a sus padres; le creen algo a alguien.

Lo segundo que enseña Pieper (1993) es que "[...] creer solamente se puede si se lo quiere" (p. 7). No solamente la inteligencia juega en esto su papel, sino también la voluntad. Debe existir un grado de apertura y una intención operante de buscar la verdad.

\subsection{Relaciones entre ética y verdad}

La nuestra es una época en la que se valora y entroniza el pluralismo. Pero ¿de qué hablamos cuando nos referimos al pluralismo? Las respuestas a esta pregunta son disímiles en función del enfoque filosófico que se le dé a la cuestión.

Como indiqué en la introducción, existe hoy una lamentable tendencia a confundir verdad con opinión. La secuencia sería: cada uno tiene "su" verdad; cada uno tiene el derecho de opinar sobre cualquier tema; ergo, la opinión de cada uno sobre cada tema será "su" verdad y, por ende, incuestionable, ya que nadie puede pretender imponer a otros "su" verdad. La verdad, así, no es algo 
que el hombre debe descubrir y servir, sino algo que construye a partir de lo que espontáneamente le viene a la cabeza en algún momento. Por eso, es más importante en los debates "tener razón" que encontrar la verdad. El relativismo en este plano es feroz y se manifiesta en numerosas frases que escuchamos cotidianamente: "nadie es dueño de la verdad", "cada uno tiene su verdad", "hay que respetar la verdad del otro", "cada uno tiene una parte de la verdad", "no hay verdades absolutas".

Ratzinger lo llamaba "la dictadura del relativismo", ${ }^{7}$ ya que sostener que "no hay verdades absolutas" implica a su vez, paradójicamente, afirmar algo con carácter de absoluto. Es decir, todo sería relativo, salvo esta misma afirmación, que no podría relativizarse. "Todo es relativo" es, para esta corriente de pensamiento, un absoluto. ${ }^{8}$ Sin embargo, la propia lógica desnuda la falsedad monumental de estas argumentaciones falaces y capciosas. Fundamentalmente, a través del principio de no contradicción, que enseña que algo no puede ser y no ser al mismo tiempo y en el mismo sentido, o, para decirlo con mayor justeza, una proposición y su negación no pueden ser ambas verdaderas al mismo tiempo y en el mismo sentido. Por ejemplo: las afirmaciones "el alma existe" y "el alma no existe" no pueden ser ambas verdaderas. O ambas afirmaciones son erróneas o una es errónea y la otra acertada; ambas acertadas es imposible.

Hoy, el "pluralista" es el relativista, para quien no hay verdades absolutas y ni siquiera propone un sincretismo que, aunque vacuo y condenado al fracaso, implicaría al menos un esfuerzo de conciliación de los pensamientos. En el fondo, intuye que ese esfuerzo entrañaría un peligro, ya que debería poner en juego "su verdad", a riesgo de tener que admitir incoherencias e inconsistencias. Lo sencillo, lo seguro, lo cómodo, lo agradable es no discutir sobre la verdad, porque cada uno tiene "su verdad".

Sin embargo, lo cierto es que hay otra noción del "pluralista", completamente alejada de la descrita. Conforme a esta, un pluralista es quien puede entablar un diálogo acerca de la verdad, sin menoscabar, discriminar ni excluir a quien piensa distinto o, incluso, opuesto. El auténtico pluralista es quien es capaz de respetar al otro sin que para ello se sienta en la necesidad de asignar a

7 "A quien tiene una fe clara a menudo se le aplica la etiqueta de fundamentalismo. Mientras que el relativismo, es decir, dejarse llevar a la deriva por cualquier viento de doctrina, parece ser la única actitud adecuada en los tiempos actuales. Se va construyendo una dictadura del relativismo que no reconoce nada como definitivo y que deja como última medida solo el propio yo y sus antojos" (Misa pro eligendo Pontifice, 18/4/2005).

8 Cfr. Sarmiento García (2003, p. 12). 
la opinión del otro la categoría de "verdad subjetiva". No respeta al otro como semejante porque tenga "su verdad", o a pesar de la "verdad" que profesa, sino porque el otro es mucho más que lo que piensa o dice. No juzga al otro, mira solo su dignidad. No recurre al consenso, acude a la comprensión. No practica tolerancia, privilegia la empatía.

Como se verá luego, entre ambos tipos de pluralismo hay un abismo cuando de opciones éticas se trata.

\subsection{Relación entre ética y libertad}

En nuestra actual cultura relativista y egocéntrica, toda búsqueda de la verdad y todo razonamiento ético configuran una amenaza para la libertad. Este concepto de libertad absoluta ve en la autoridad una amenaza, y en el Estado, una amenaza organizada. Sin embargo, como bien señala López Azpitarte (2003),

la moral no es la frontera que encierra y esclaviza a la libertad, algo ajeno y opuesto a ella, como un adversario que quisiera destruirla. Es, por el contrario, el cauce que orienta su ejercicio, la luz que ilumina el sendero para que llegue a conseguir precisamente lo que quiere: modelar lo que somos instintivamente, como ofrecimiento primario de la naturaleza, para construir la imagen de persona que se ha proyectado. (p. 105)

En una reciente película, titulada El silencio del pantano (2019), el protagonista, un escritor de novelas, está firmando ejemplares de su último libro. Luego de la presentación, entabla el siguiente diálogo con una de sus admiradoras mientras le dedica un ejemplar:

- ¿Le puedo hacer una pregunta?

-Claro, si me llamas de tú.

-El protagonista... Quiero decir que no se explica qué le pasa, si es que tiene un trauma o algo así. Y tampoco sabemos nada de su pasado. ¿Va a contarlo en algún libro?

-No. No lo tengo previsto, la verdad.

-Entonces, nunca vamos a saber por qué mata.

-Porque puede.

En este diálogo queda reflejado el núcleo del concepto actual de "libertad": todo lo que puede hacerse es válido que se haga. Si se puede, se hace. Y este razonamiento no es solamente la base de los comportamientos individuales, sino también de algunas teorías científicas. En el campo de la bioética, sobre el que 
volveré más adelante, hay demasiados ejemplos de esto. La explicación es clara: se considera a la libertad desasida de la responsabilidad, que es su contracara. Una libertad que fundamenta derechos, pero que jamás origina obligaciones. Piense cada uno de los que leen esto cuántas conferencias ha escuchado y textos ha leído sobre "derechos humanos" y cuántos sobre "deberes del hombre". Ello ha llevado a Vigo (2000) a sostener:

En una lectura apropiada de los derechos humanos fundamentales no hay lugar para versiones individualistas que terminen marginando aquello que les corresponde a las sociedades que se benefician con integrar, $\mathrm{y}$, asimismo, se debe recordar que están implícitos no sólo los límites de aquellos derechos, sino también los "deberes jurídicos fundamentales". (p. 224)9

Sin embargo, lo cierto es que la auténtica libertad reconoce y respeta límites que la ordenan desde fuera (las leyes) y desde dentro (las virtudes). Enseña, por ello, Estanislao Karlic que la libertad está más que en la posibilidad de elegir en el acto de elegir lo bueno. ${ }^{10}$ No somos en realidad auténticamente libres porque tenemos la posibilidad de elegir entre varias opciones, sino cuando elegimos la correcta, la que habrá de dotarnos de plenitud, la que habrá de convertirse en un bien para nuestra vida. Las opciones éticas valiosas nos liberan, así como las erróneas nos esclavizan haciéndonos perder libertad. ${ }^{11}$ Es lo que también enseña Palma Bufill (1999):

Existe una estrecha correlación entre libertad y moralidad; la libertad es la capacidad de dirigir los propios actos al bien propio del hombre, radicado en el amor de Dios y del prójimo; la moralidad es la proporción que esos actos guardan con ese bien. (p. 98)

9 En esta línea, sostiene Lorenzetti (1998): “[...] esta letanía de pretextos hunde en realidad sus raíces en la moral individualista, no tiene en cuenta para nada las obligaciones sociales [...] Mucho más eficaz es el convencimiento personal y la conciencia de ser miembro de una comunidad en la que se tiene el derecho de recibir, pero también de dar de lo propio en la medida de las posibilidades” (p. 247).

10 Cita extraída de la conferencia dictada por Estanislao Karlic en la XII Reunión de Profesionales Católicos, organizada por la Acción Católica Argentina, del 20 al 22 de junio de 1985 en la provincia de Catamarca.

11 "Hay una relación íntima y profunda entre la norma ética y la buena consecuencia: el hombre se hace mejor hombre cuando la sigue, y se degrada como hombre cuando le da la espalda". (Sada Fernández, 2011, p. 35) A su vez, Ayllón (2008) explica: "Pertenece a la perfección de la libertad el poder elegir caminos diversos para llegar a un buen fin. Pero inclinarse por algo que aparte del fin bueno -en eso consiste el mal- es una imperfección de la libertad" (p. 26). 
En ese maravilloso libro que es El hombre en busca de sentido, Frankl (1986) describe certeramente esa dualidad: "¿Qué es, en realidad, el hombre? Es el ser que siempre decide lo que es. Es el ser que ha inventado las cámaras de gas, pero asimismo es el ser que ha entrado en ellas con paso firme musitando una oración” (p. 87). Lo mejor y lo peor de la condición humana.

En definitiva, como bien afirma Soto Kloss (2002),

la moral incide nada menos que en el uso de la libertad del ser humano, libertad que "especifica" el ser del hombre, de lo humano, y que guiada por la razón -el otro elemento que especifica lo humano, junto con su sociabilidad y su carácter de creatura- permite una vida lograda, buena, virtuosa, y el logro de la felicidad, que es la máxima aspiración de los humanos. (pp. 9-10)

\subsection{Relación entre ética y virtud}

El obrar ético reclama la virtud, que no consiste en acciones aisladas, sino en un hábito que supone la educación de la conciencia para el obrar moralmente recto. Al respecto, enseña Rodríguez-Arana Muñoz (2004):

Así, para Aristóteles no nos debemos conformar con saber lo que es el valor y la justicia, sino que debemos ser valientes y justos. De la misma manera, queremos estar sanos, supongo, más que saber en qué consiste la salud. Por eso, en el pensamiento clásico aristotélico, el concepto filosófico de virtud se nos presenta como un hábito, una costumbre que se adquiere mediante la repetición de actos semejantes [...]. (p. 35)

El dato antropológico juega acá un papel esencial, ya que es crucial la clara conciencia de lo que significa propiamente el ser humano.

La lucha interior en el hombre que quiere obrar el bien, convocado a ello por la propia conciencia, y, sin embargo, se inclina al mal, es el lamento paulino: "No hago el bien que quiero y hago el mal que no quiero" (Rom. 7, 19). Por eso, no encontramos sosiego cuando nos apartamos del camino que nos lleva a ser lo que debemos ser, usando mal nuestra libertad y nuestra voluntad. De allí que Camus (1953) haya dicho que "el hombre es la única creatura que se niega a ser lo que es" (p. 16).

No pocas veces, como explica Ayllón (2008), es un problema de falta de fortaleza. Así, sostiene: 
Sabemos que los seres humanos traicionan a menudo sus propias convicciones éticas, que no hacen el bien ni evitan el mal que deberían. En esa debilidad constitutiva se manifiesta también la necesidad de la fortaleza [...] No es que ya no queramos, es que no queremos a fondo, queremos sin fuerza. No es una experiencia de falta de libertad, sino de falta de fuerzas. (p. 69)

La exigencia de la virtud desaparece cuando quien marca la senda es el pragmatismo utilitarista. ¿Qué habito podría formarse interiormente cuando lo que se busca no es la coherencia con una verdad en la que se cree, sino la satisfacción de un interés puramente coyuntural? ¿Para qué atarse a un obrar virtuoso si la verdad sería aquello que se actúa en cada ocasión, sin referencias que trasciendan al sujeto actuante?

Por el contrario, cuando tomamos conciencia de que un dato antropológico es una cierta inclinación al mal, con la que todo ser convive interiormente y la mayoría combate, advertimos la necesidad de encontrar algún punto de apoyo al cual asirnos, alguna luz que ilumine el camino correcto. Para poder decir "no hago el bien que quiero y hago el mal que no quiero", es menester definir primero cuál es ese bien que quiero y cuál es ese mal que no quiero. La conclusión siempre será la misma: hacer habitualmente el bien que quiero presupone virtud; producir habitualmente el mal indeseado solo puede provenir de un vivir dominado por el vicio.

\section{Entonces, ¿una ética o muchas éticas?}

Dicho lo anterior, corresponde ahora entrar de lleno en la primera pregunta esencial: ¿hay una ética o muchas éticas?

Entiendo que solo pueden existir dos respuestas a esta pregunta: o hay una sola ética objetiva, universal e inmutable, o hay tantas éticas como sujetos actúan.

No pocas personas sostienen la segunda respuesta intelectualmente y muchas más la vivencian. Es el relativismo llevado hasta las últimas consecuencias. La negación de los límites a la libertad. La entronización del sujeto y su interés meramente personal. La afirmación del "yo" como núcleo central del existir. Con profundidad explica Santiago (2002):

La concepción del individualismo está estrechamente unida a la de la autonomía moral. El individuo no sólo está "desvinculado" de sus semejantes, sino que está sólo librado a su propia voluntad e intereses, autónomamente configurados por él y sin sujeción a ninguna naturaleza [...] La relación básica con el otro no es de amistad sino de mera coexistencia de intereses, cuando no de competencia, hos- 
tilidad o dominación. El despliegue ilimitado del propio yo, en todas sus potencialidades, la búsqueda exclusiva del propio interés individual, es la fuerza que mueve fundamental y radicalmente la vida del hombre. La ambición personal y el deseo incesante de predominio sobre los demás son los móviles permanentes de la existencia humana. (pp. 52-53)

Este punto es vital en la enseñanza de la Ética porque de él depende todo lo demás. Si hay una ética, entonces el desafío ineludible es buscarla, encontrarla y vivir conforme a ella. Por el contrario, si cada uno posee su propia ética, aquel empeño sería tan absurdo como innecesario. Ahora bien, si la palabra clave acá es "coherencia", será menester preguntar a los cultores de la ética individualista cómo podría darse la convivencia humana entre personas para las cuales la definición del bien y del mal es absolutamente subjetiva. Porque está claro que si se sostiene que cada persona sigue una idea subjetiva de la ética, y esto es correcto y válido, no sería justo ni aceptable que una de esas casi infinitas éticas sea impuesta por sobre las demás. Por el contrario, pretender erigir una ética determinada por sobre las demás sería un acto del más severo autoritarismo.

A esta visión egocéntrica se opone la de quienes sostienen que existe una sola ética posible. Así, sostiene Sada Fernández (2011): "La recta razón nos lleva a sostener que NO HAY SINO UNA ÉTICA: LA QUE SE APOYA EN LA REALIDAD, EN EL SER DE LAS COSAS, EN LA NATURALEZA HUMANA" (p. 33). ${ }^{12}$ Desarrollaré este pensamiento en el punto siguiente.

En realidad, está claro que la convivencia humana sería imposible si, siguiendo algún método, no se definieran determinados comportamientos como deseables u obligatorios. El mismo concepto de "autoridad" se erige sobre este fundamento. La clave entonces será cómo llegar a esa única ética que todos deberíamos respetar y bajo cuyas prescripciones deberíamos construir nuestras existencias.

\section{La segunda pregunta}

En su discurso a representantes de la sociedad británica del 17 de septiembre de 2010, en Westmisnter Hall, el papa Benedicto XVI (2010) formuló la siguiente pregunta: " $¿ E n$ nombre de qué autoridad pueden resolverse los dilemas morales?”. Es esta la segunda pregunta esencial en la enseñanza de la Ética.

¿Hay una ética o muchas éticas? Si hay muchas, hay tantas como personas existen, lo que tornaría imposible la convivencia humana. Si se acuerda en que

12 Énfasis en el original. 
solo hay una, ¿cuál es? ¿Quién la define? ¿De dónde obtengo su contenido? O, para decirlo más coloquialmente, ¿quién dice qué está bien y qué está mal? Es la pregunta de Benedicto XVI.

Es una pregunta no exenta de dificultades y complejidades. Como bien sostiene Soto Kloss (2002),

Saber lo que es bueno y lo que no es, no siempre es fácil; del primer principio de la razón práctica, como es "el bien ha de hacerse y buscarse y el mal ha de evitarse”, que es captado por el hábito natural de la sindéresis, y evidente por sí mismo, y que todos, en último término, aceptan, no se sigue que sea sencillo reconocer siempre, en las concretas y tan diversas circunstancias de la vida, lo que es bueno y qué no lo es. (p. 11)

Se puede responder a ella desde distintos planos. En el plano teológico, para el cristianismo, por ejemplo, no existe duda alguna acerca de que los mandatos éticos tienen una relación inescindible con la verdad y, para el cristiano, la verdad no es una doctrina sino una Persona. "Yo soy el camino, la verdad y la vida", dice Jesús (Jn. 14, 6). El cristiano encuentra el contenido de la ética en la Verdad que profesa. Por ello, en este plano, como bien dice Scarponi (2018), "[...] surge la verdad ética fundamental del Evangelio: Sean perfectos como es perfecto el Padre celestial de ustedes (Mt. 5, 48)” (p. 32).

Pero también puede hallarse en el plano filosófico, a partir, por ejemplo, del desarrollo aristotélico-tomista, y este razonar no pertenece al plano religioso, de modo que cualquier persona, aun agnóstica o atea, puede suscribirlo. ${ }^{13}$ Por ello ha podido decirse de la ética aristotélico-tomista que "[...] no es verdadera porque lo diga la fe cristiana, sino que la fe cristiana la adopta porque es verdadera" (Sada Fernández, 2011, p. 34). ${ }^{14}$ Es importante comprender esto y tener claro sus reales alcances. Al respecto, es muy ilustrativo el Documento "En busca de una ética universal: una nueva mirada sobre la ley natural”, cuyo estudio recomiendo vivamente y en el que puede leerse:

13 "Este denominador común -se refiere a los iusnaturalismos- es la existencia de una naturaleza humana que es universal, y en ella podemos limitar nuestra afirmación sin necesidad de 'ascensos' hacia posiciones teónomas, que no negamos, que coincidimos, pero que no podemos 'imponer' a quien carezca de fe". (González Castro, 2000, p. 47)

14 Al respecto, Barazzutti (2006) sostiene: "Es sabido que la ética cristiana está basada en la Escritura, así como la proclama y la interpreta oficialmente magisterio de la Iglesia. Sin embargo, no ignora ni pasa por alto los reclamos de la razón y las enseñanzas de la experiencia. Sin dejar de ser cristiana es, pues, ética humana, más humana que cualquier otra ética religiosa y no religiosa" (p. 12). 
[...] el cristianismo no tiene el monopolio de la ley natural. En efecto, fundada sobre la razón común a todos los hombres, la ley natural es la base para la colaboración entre todos los hombres de buena voluntad más allá de sus convicciones religiosas. (Comisión Teológica Internacional, 2011, p. 41)

Como complemento de lo dicho, escuchemos a Cicerón, quien escribió lo siguiente un siglo antes de Cristo:

Hay una ley verdadera, la recta razón inscripta en todos los corazones, inmutable, eterna, que llama a los hombres al bien por medio de sus mandamientos y los aleja del mal por sus amenazas; pero ya sea que ordene o que prohíba, nunca se dirige en vano a los buenos ni deja de atemorizar a los malos. No se puede alterar por otras leyes, ni derogar alguno de sus preceptos, ni abrogarla por entero; ni el Senado, ni el pueblo pueden librarnos de su imperio; no necesita intérprete que la explique; es la misma en Roma que en Atenas, la misma hoy que mañana y siempre una misma ley inmutable y eterna que rige a la vez a todos los pueblos y en todos los tiempos. (Cicerón citado en Novoa Monreal, 1967, p. 9)

\section{Esta ley natural}

[...] inhiere en todos los hombres y obliga a todos los hombres; es una ley universal en el espacio y en el tiempo. Para que la ley natural no fuese universal sería preciso que las inclinaciones o tendencias naturales variasen en el hombre, que variase su condición de persona (raíz del deber-ser) y que variasen los fines naturales o la estructura de la razón práctica. Pero esto es imposible, porque todo ello forma parte la naturaleza humana que, por ser la estructura fundamental del ser humano -aquella que lo constituye como hombre- es invariable y universal [...]. (Hervada, 2000, p. 143)

La otra respuesta posible a nuestra segunda pregunta es el consenso: la verdad y la única ética aceptable es aquello en lo que nos ponemos de acuerdo. Es entonces el consenso aquella "autoridad" que permite resolver los dilemas morales. Como es imposible coexistir bajo infinidad de opciones éticas considerándolas a todas igualmente válidas, y como no es aceptable que las nociones de "bien" y de "mal" vengan dadas por creencia religiosa alguna que trascienda al hombre, el único camino posible es el acuerdo.

Esta postura, explicada acá de un modo extremadamente sintético y simplificado en virtud del espacio y del objetivo de estas líneas, presenta no pocas dificultades.

En primer lugar, con relación al método: ¿cuál sería el camino para alcanzar 
el consenso? A poco que se analiza el tema se llega pronto a una respuesta tan evidente como insatisfactoria: la única herramienta que proporcionan para ello las democracias actuales es el debate parlamentario. Finalmente, las nociones del bien y del mal serían dadas por el poder de representación, cualquiera sea su diseño. En nuestro país, por ejemplo, los dilemas morales serían resueltos por nuestros legisladores, diputados y senadores en forma de leyes. Sin embargo, en nuestro esquema constitucional, una ley podría ser finalmente tachada de inconstitucional -y con ello perdería vigencia real- por tres miembros de la Corte Suprema de Justicia de la Nación en un hipotético fallo dividido. En tal caso, la noción del bien y del mal sería, en definitiva, el parecer de tres personas.

En segundo lugar, está el problema de la vigencia del consenso en el tiempo y en el espacio. Hoy se consideran derechos lo que hasta no hace mucho se consideraban perversiones. Como bien dice López Azpitarte (2003):

hoy se aceptan conductas que en épocas anteriores estaban condenadas, y lo que antes no era lícito a lo mejor hoy resulta posible. Una moral que cambia y evoluciona pierde por completo su credibilidad, pues no tiene razones suficientes para exigir una confianza plena. (p. 22)

Además, en este momento, formas de comportamiento que en algunos países se consagran como derechos en otros se castigan con la pena de muerte. Si la palabra clave es "coherencia", ¿estaba "bien" que las mujeres no votaran en la Argentina hasta la segunda mitad del siglo XX? Porque eso era lo que decían las leyes en ese momento vigentes, fruto del consenso. ¿Estaba bien la esclavitud en el pasado, pero no está bien ahora? Consideramos hoy que la pederastia “está mal”, ¿pero no podría acaso "estar bien” en el futuro si nos pusiéramos de acuerdo al respecto? Y para que nadie se escandalice con el ejemplo, recuerdo que en estos precisos momentos en nuestro país existen proyectos que pretenden convertir un delito en un derecho, sin escalas.

Suelo preguntarles a mis alumnos de posgrado si piensan que, a partir de los datos antropológicos que se consideran indubitados (ser individual de naturaleza social, libre, trascendente, espiritual), el hombre de hoy es ontológicamente (no culturalmente) diferente al de los siglos anteriores, y la respuesta es negativa. También les pregunto si antropológicamente hablando un argentino es ontológicamente (no culturalmente) diferente a un africano o a un asiático, y la respuesta también es negativa. Entonces, si el hombre es esencialmente el mismo a lo largo del tiempo y a lo ancho del planeta, ¿por qué deberíamos aceptar soluciones éticas diferentes ante un mismo dilema? 
Aparece acá, entonces, la referencia a lo cultural como legitimante de estas diferencias de criterio. Está muy bien reconocer el indudable hecho de la multiplicidad de manifestaciones culturales que siempre han existido y van a existir, pero el problema comienza cuando pretende sostenerse que todo es cultural. Si la palabra clave es "coherencia", habría que aceptar que "estaba bien" que en algunas épocas se ofrecieran niños a los dioses en holocausto, o que se arrojara a los recién nacidos al vacío si tenían alguna discapacidad, o que se discriminara groseramente a las personas por el color de su piel.

Cabe así preguntarse: ¿lo moral depende de la época en la que se vive o del país en el que se habita? Suele existir aquí una confusión entre las influencias y condicionamientos que las diferentes culturas producen y lo que es naturalmente insoslayable. Debe distinguirse, por ello, entre las manifestaciones culturales que implican indiferentes éticos y aquellas que sí deben evaluarse desde el plano moral.

En tercer lugar, en cuanto al contenido, ¿cuál sería el límite entre lo moralmente aceptable e inaceptable? Ninguno más allá del consenso. Sin embargo, hay un trasfondo en la cultura relativista que no es posible soslayar: la tendencia a la ausencia de límites. Como en el diálogo cinematográfico antes comentado, en el que el protagonista de la novela mataba simplemente porque podía, la máxima hoy sería "si se puede, se hace". El campo de la bioética es un buen ejemplo de ello. Multiplicidad de prácticas se llevan a cabo sin que se admita siquiera una lectura sobre su eticidad. El aborto, la manipulación genética, la fecundación artificial, el mantenimiento artificial o mecánico de la vida (ensañamiento terapéutico), el congelamiento de embriones, la maternidad sustitutiva, la donación de esperma, la eutanasia, son todos ejemplos de prácticas que se presumen éticamente lícitas simplemente porque la tecnología actual permite llevarlas a cabo. Empiezan a asomar otras aún más cuestionables, como la clonación de humanos o la gestación de niños "a la carta". Pareciera que el plano científico nada tiene que preguntar al teológico ni al filosófico.

En definitiva, y siempre simplificando el planteo al solo efecto de facilitar la comprensión del núcleo del problema, a la pregunta de Benedicto XVI podemos bridar dos respuestas: el consenso o la ley natural. ${ }^{15}$ Lo dice muy bien Alexy: "El problema central de la polémica acerca del concepto de derecho es la relación entre derecho y moral. A pesar de una difusión de más de dos mil años, siguen existiendo dos posiciones básicas: la positivista y la no-positivista" (Vigo, 2006, p. 7).

15 Insisto en que se está simplificando el planteo con el objetivo de permitir que la atención se centre no en las discusiones propias de la filosofía del derecho, sino en una determinada metodología de 
Para la teoría del consenso, en cualesquiera de sus variantes, la ley es en última instancia la respuesta. Esta teoría, hija del positivismo, no reconoce, más allá de la ley, otra autoridad que pueda dirimir los dilemas morales. ${ }^{16}$

Por el contrario, el iusnaturalismo invita a trascender lo legal o, mejor, exige que lo legal se enraíce en lo natural. En esta línea, el jurisconsulto Paulo decía: "El derecho no se extrae de la norma, sino de lo que el derecho es, se hace la norma" (Paulo citado en Urrutigoity, 1995, p. 224). El derecho, para ser propiamente tal, debe ser justo. ${ }^{17}$ Lo justo es, siempre siguiendo a Paulo, el "analogado principal”, mientras que el derecho en sentido objetivo y el derecho en sentido subjetivo son "analogados secundarios". Cuando afirmamos que la norma debe hacerse de lo que es justo, estamos reconociendo que el concepto mismo de "justicia" tiene un fundamento que trasciende lo legal positivo, de lo contrario, sería una petición de principios.

No faltan, por supuesto, quienes sostienen la "amoralidad" del derecho, o la "neutralidad" del derecho respecto a la moral. A ello responde Busso (2015):

Desde nuestro punto de vista, es imposible admitir esta forma de amoralidad del derecho. Si por amoralidad del derecho se entiende la separación de hecho, es evidente que existe como criterio distinto de valoración [...] Pero si por amoralidad del derecho, se entiende que nada tiene que ver con la moral, como parece pretender la Escuela de Viena, esto no puede ser admitido [...] no podría permitirse una separación objetiva entre la moral y el derecho, porque éste debe ser informado por la justicia, es decir por la moralidad. (pp. 238-239)

\section{Vigo (2000) resalta que}

en las dos últimas décadas, el tema de los principios jurídicos como un ámbito integrativo del ordenamiento jurídico, pero diferenciado de las reglas o normas jurídicas, ha adquirido una importancia notable en el campo de la teoría general

enseñar la Ética. Con esto quiero decir que no se me escapa la opinión de juristas de la jerarquía de Massini Correas (2005), para quien "[...] hoy en día ya no es posible dividir las filosofías del derecho simplemente en positivistas y iusnaturalistas, aun cuando se introduzcan variantes dentro de cada uno de los términos de la clasificación" (p. 3).

16 Para una profundización de los diversos tipos de positivismo, ver Royo Marín (2007, pp. 81 y ss.).

17 Certeramente afirma Massini Correas (1987): "[...] si la 'justicia' objetiva es la forma propia del derecho, si es aquello que lo hace ser eso que es y no otra cosa, solamente a lo 'justo' puede llamarse 'derecho' en su sentido propio; lo que no sea 'justo' será prepotencia, brutalidad salvajismo, pero no puede hacerse acreedor al calificativo de 'derecho', que desde siempre ha designado a uno de los bienes más elevados de la convivencia humana” (p. 22). 
o de la filosofía del derecho, a tal punto que con justicia se ha podido hablar de una nueva "edad de oro" de los principios. (p. 1)

Para luego afirmar que: "[...] dicha problemática aparece íntimamente ligada al jusnaturalismo; concretamente, a la distinción entre el derecho escrito, contingente y establecido como tal por los hombres, y el derecho universal, necesario y simplemente reconocido por los hombres en ese carácter" (Vigo, 2000, p. 3). ${ }^{18}$ La distinción es esencial: hay derechos que el Estado otorga y hay otros que el Estado reconoce. La positivización de estos últimos no debe confundirnos, ya que siguen siendo indisponibles para el legislador. Cuando se atraviesa esta línea, se cae sin remedio en el autoritarismo, en el ejercicio del poder sin la razón.

Al respecto, Santo Tomás explicaba:

La legislación humana sólo posee carácter de ley cuando se conforma a la justa razón; lo cual significa que su obligatoriedad procede de la ley eterna. En la medida en que ella se apartase de la razón, sería preciso declararla injusta, pues no verificaría la noción de ley; sería más bien una forma de violencia. (Summa theologiae, 1-2, q. 93, a. 3 ad 2)

En esta línea de razonamiento, Sada Fernández (2011) indica que "el bien moral es, entonces, el bien conveniente a la naturaleza humana, según el dictamen de la recta razón” (p. 28).

El mismo Benedicto XVI dejaba esto muy claro en su ya citado discurso en el Parlamento británico: "La tradición católica sostiene que las normas objetivas para una acción justa de gobierno son accesibles a la razón, prescindiendo del contenido de la revelación". No es, queda claro, una "cuestión religiosa".

\section{Conclusiones}

En otra película, La cabaña (2017), se da el siguiente diálogo entre un hombre

18 En la misma línea, Cassagne (2015) ha sostenido: "La pretensión de reducir el fenómeno jurídico exclusivamente a la ley positiva se ha batido en retirada y ya no quedan casi juristas que sostengan los dogmas básicos del positivismo puro. Esa corriente ha cedido a raíz del reconocimiento de la prevalencia de los principios generales, fundados en principios de la ley natural (la justicia, la equidad, y otros valores de naturaleza eminentemente moral) (V. gr. el principio general de la buena fe)" (p. 18). Debo destacar acá el invalorable aporte que sobre el estudio de la importancia de los principios en el mundo del derecho han efectuado en nuestro país juristas de la talla de Juan Carlos Cassagne, Alfonso Santiago, Jorge H. Sarmiento García y Rodolfo L. Vigo, entre otros. 
(Mack), sumido en depresión por la pérdida de su hijo pequeño, y una joven que representa al Espíritu Santo (Sarayu) mientras trabajan en un jardín:

Sarayu: -Dime esto: ¿cuánta confianza tienes en tu habilidad de discernir entre el bien y el mal?

Mack: -Suele ser muy obvio.

Sarayu: $-i Y$ cómo determinas tú que algo es bueno?

Mack: -Si me ayuda, o a las personas que amo.

Sarayu: -iY el mal?

Mack: -Si me perjudica, si daña a alguien que yo amo.

Sarayu: -Entonces... ¿lo que afirmas es que eres el juez?

Mack: -Sí, eso creo.

Sarayu: - ¿Nunca te equivocaste o cambiaste de opinión con el tiempo?

Mack: -Claro.

Sarayu: -Y hay millones que lo hacen. Hay quienes determinan lo que uno cree que es el bien o el mal. Y si tu bien choca con el mal de tu vecino, comienzan las peleas, se desatan muchas guerras. ¿Por qué todos insisten en imitar a Dios?

Este diálogo refleja, en una muy buena medida, la situación del hombre actual en tiempos de relativismo. El protagonista vincula la noción de "bien" y de "mal" con su propio beneficio (si me ayuda, si me perjudica) y no tiene problema alguno en reconocer que su medida para juzgar es ese pragmatismo utilitarista (soy el juez). Finalmente, reconoce que en esa determinación del bien y del mal se equivocó o cambió de opinión a lo largo de su vida. En definitiva, una noción del bien y del mal personal e inestable, individualista y coyuntural.

Pero el diálogo transcrito refleja con crudeza un condimento aún más asombroso, propio de nuestra época: incluso autodefiniéndose juez de la definición del bien y del mal y reconociendo que en tal cometido se equivoca o cambia de parecer, acepta ambos extremos sin conflicto interior alguno. Ahí queda reflejada la clave de toda lectura de nuestra situación actual: la aspiración a que el obrar individual, aquí y ahora, sea la pauta de comportamiento correcta. Sin referencias trascendentes ni cuestionamientos de conciencia; sin compromisos con el futuro; sin apertura al cotejo con otras miradas.

Si se parafrasea a Pío XII, que en términos religiosos sostuvo que el mayor pecado del hombre de hoy es haber perdido la noción de pecado, podría decirse que, en términos antropológicos, el mayor déficit del hombre actual es haber extraviado el camino hacia su propia plenitud. Y lo ha hecho por seguir los cantos de sirena ya enunciados: confundiendo la verdad con la opinión; considerando la libertad como un hacer lo que da la gana, sin vinculación alguna con la responsabilidad; desechando la virtud por verla como una mojigatería 
pasada de moda; y, lo que es más increíble, anestesiando la razón para guiarse por el instinto o, peor aún, por lo antinatural.

Un gran maestro como fue don Pedro J. Frías (1992) escribió: "Desconfío de toda acción política que no interrogue a la moral, porque la moral es arquitectónica respecto de la política” (p. 88). Lo mismo es predicable del derecho, de la economía, del arte y, en fin, de toda realidad humana. La moral debe ser arquitectónica respecto a cualquier actividad del hombre.

Volveremos acá a plantear la cuestión en dos planos. En el plano teológico, Juan Pablo II sostuvo en la Conferencia Inaugural de Puebla (1979), con palabras dirigidas a los pueblos latinoamericanos:

La nuestra es, sin duda, la época en que más se ha escrito y hablado sobre el hombre, la época de los humanismos y del antropocentrismo. Sin embargo, paradójicamente, es también la época de las más hondas angustias del hombre respecto de su identidad y destino, el rebajamiento del hombre a niveles antes insospechados, época de valores humanos conculcados como jamás lo fueron antes. ¿Cómo se explica esta paradoja? Podemos decir que es la paradoja inexorable del humanismo ateo. Es el drama del hombre amputado de una dimensión esencial de su ser -el absoluto- y puesto así frente a la peor reducción del mismo ser. (Conferencia Inaugural de Puebla, 1979) ${ }^{19}$

Para el ser religioso, no hay bien que no remita al Bien.

En el plano filosófico, es perfectamente posible llegar al mismo diagnóstico a través de la razón iluminada por una recta conciencia.

La tarea hoy, en nuestros claustros, es ciclópea en esta materia, no pocas veces subestimada. La enseñanza de la Ética no puede estar ausente en ningún nivel educativo y, mucho menos, en el universitario. Debe estarlo como materia y como contenido transversal; como asignatura central, nuclear, porque en la tarea de educar personas lo esencial es ayudarlas a llegar a la plenitud del ser y después, mucho después, transmitir conocimientos técnicos o profesionales; como contenido transversal, porque todos y cada uno de los aprendizajes particulares deben ser atravesados por el componente moral.

Obviar esta dimensión en la tarea educativa es quedar a mitad de camino, olvidar que como educadores formamos personas, ignorar que nuestras sociedades necesitan, como el oxígeno, personas moralmente intachables, ciudadanos ejemplares, líderes incorruptibles. Y esa batalla se gana o se pierde en las familias y en las aulas.

19 Mensaje Inaugural de la III Conferencia General del Episcopado Latinoamericano (Puebla). 
El desafío hoy es gigantesco. No basta con enseñar el camino correcto, es necesario llegar al corazón y a la inteligencia de nuestros alumnos para conquistar su voluntad para emprender ese camino. No alcanza con mostrarlo, es imperioso transmitirles el gozo de transitarlo.

Para ello, lo primero a entender es que esa conquista del corazón y de las inteligencias jamás debe pasar por las imposiciones ni por -discúlpeseme lo coloquial- las "bajadas de línea". No es con argumentos dogmáticos como captaremos su atención. La clave es, a mi juicio, seguir una estrategia jalonada por las instancias que menciono a continuación.

Primero, preguntar y, sobre la respuesta, volver a preguntar, y así sucesivamente hasta que el alumno advierta que con su idea original no puede brindar respuestas satisfactorias. Hay que evitar acá la tentación de pontificar sobre la "respuesta adecuada" y dejar que él avance por sí mismo hacia su descubrimiento.

Luego, como segundo paso, una vez que las preguntas no puedan ser respondidas con la idea original, mostrar respuestas posibles y dejar que el mismo alumno vaya desgranando cada una de ellas, sus pro y sus contras, sus inconsistencias e incoherencias o su solidez.

El tercer momento, el crucial, comienza cuando el alumno ha logrado dar por sí mismo (quizás con alguna ayuda adicional) con la respuesta adecuada. El camino, un camino nuevo, se abre ante sus ojos. Para llegar hasta acá, ha debido dejar de lado sus convicciones previas y ha quedado como "tabula rasa". Debe comenzar a escribir su nueva historia con nuevas herramientas. La razón lo ha traído hasta acá. Es el momento de conquistar su voluntad de comenzar a transitar esa nueva senda antes inhabitada y ejercer así una libertad que habrá de llevarlo a la plenitud. Es la hora del ejemplo, de infundir confianza, de explicar que todo ser humano puede construir, con los escombros de sus errores y desatinos, un nuevo hogar para sus esperanzas e ilusiones.

Y allí, en esta última etapa, hay que procurar que entiendan, existencialmente, aquello que tan maravillosamente escribía José Luis Martín Descalzo (2000): "Sí, todo hombre debe dar dos pasos: el primero, aceptarse a sí mismo. El segundo, exigirse a sí mismo. Sin el primero, caminamos hacia la amargura; sin el segundo, hacia la mediocridad" (p. 194).

La enseñanza de la Ética en tiempos de relativismo sirve precisamente para esto: para entender que, a partir de lo que somos, podemos y debemos construir lo que debemos ser. ${ }^{20}$

20 Se trata, en definitiva, como bien explica Calvez (1993), de "[...] la búsqueda de orientaciones éticas: posturas coherentes o criterios de acción relacionados con nuestro destino mismo y en respuesta al 


\section{Bibliografía}

Ayllón, J. R. (2008). Ética razonada. Madrid: Palabra.

Barazzutti, L. (2006). Conversaciones sobre ética cristiana. Buenos Aires: San Benito.

Benedicto XVI. (26 de septiembre de 2010). La ética, el desafío para la democracia. Discurso en el Parlamento británico. L'Osservatore Romano. http://www.vatican.va/content/benedict-xvi/es/ speeches/2010/september/documents/hf_ben-xvi_spe_20100917_societa-civile.html.

Busso, A. D. (2015). El derecho natural y la prudencia jurídica. Buenos Aires: Universidad Católica Argentina.

Calvez, J. I. (1993). Una ética para nuestra sociedad en transformación. Buenos Aires: Ciudad Nueva. Camus, A. (1953). El hombre rebelde. Buenos Aires: Losada.

Cassagne, J. C. (2015). Los grandes principios del derecho público. Buenos Aires: La Ley.

Comisión Teológica Internacional. (2011). En búsqueda de una ética universal. Buenos Aires: EDUCA.

Conferencia Episcopal Latinoamericana. (1979). La evangelización en el presente y en el futuro de América Latina. Puebla de los Ángeles, México.

Frankl, V. (1986). El hombre en busca de sentido. Barcelona: Herder.

Frías, P. J. (1992). El Derecho argentino entre 1941 y 1991. Córdoba: Academia Nacional de Derecho y Ciencias Sociales.

García, J. J. (2006). Compendio de Bioética. Buenos Aires: Librería Córdoba.

González Castro, M. A. (2000). Paradigna jusnaturalista. Córdoba: Advocatus.

Hervada, J. (2000). Introducción crítica al Derecho Natural. Colombia: Temis.

Juan Pablo II. (14 de septiembre de 1998). Encíclica Fides et ratio.

López Azpitarte, E. (2003). El nuevo rostro de la moral. Buenos Aires: San Benito.

Lorenzetti, L. (1998). La Moral. Buenos Aires: San Pablo.

Martín Descalzo, J. L. (2000). Razones para el amor. Salamanca: Ediciones Sígueme.

Massini Correas, C. I. (1987). El Derecho, los derechos humanos y el valor del Derecho. Buenos Aires: Abeledo-Perrot.

Massini Correas, C. I. (2005). Filosofía del Derecho. Buenos Aires: LexisNexis.

Novoa Monreal, E. (1967). ¿Qué queda del Derecho Natural? Buenos Aires: Depalma.

Palma Bufill, J. A. (1999). Manual de moral fundamental. Buenos Aires: Ábaco.

Pieper, J. (1993). Creer. Revista Gladius, (26).

Ratzinger, J. (18 de abril de 2005). Homilia en la Misa pro eligendo Pontifice.

Rodríguez-Arana Muñoz, J. (2004). Ética, Poder y Estado. Buenos Aires: RAP.

Royo Marín, A. (2007). Teología moral para seglares. Madrid: BAC.

Sada Fernández, R. (2011). Curso de ética general y aplicada. México: Minos.

Sánchez, A. M. (2017). Ética y Derecho. Revista IUS, 1(13), 117-134.

Santiago, A. (h) (2002). Bien común y derecho constitucional. Buenos Aires: Ábaco.

Sarmiento García, J. H. (2003). La ética y los jueces. Mendoza: Ediciones Diké.

Scarponi, C. A. (2018). Fundamentos teológicos de la moral. Buenos Aires: Ágape.

Sotelo de Andreau, M. G. (2007). La ética, la corrupción y la función pública. Corrientes: Universidad de la Cuenca del Plata.

más profundo llamado que llevamos grabado en nosotros mismos" (p. 5). 
Soto Kloss, E. (2002). La moral, hoy. Santiago de Chile: Academia de Derecho, Universidad Santo Tomás.

Urrutigoity, J. (1995). El derecho subjetivo y la legitimación procesal administrativa. En Sarmiento García, J. H., Prtiz, O., Ábalos, M. G., Urrutigoity, J., Estudios de Derecho Administrativo. Buenos Aires: Depalma.

Vigo, R. L. (h) (2000). Los principios jurídicos. Buenos Aires: Depalma.

Vigo, R. L. (h) (2006). Perspectivas iusfilosóficas contemporáneas. Buenos Aires: LexisNexis. 